\title{
Vertical cell movement is a primary response of intertidal benthic biofilms to increasing light dose
}

\author{
R. G. Perkins ${ }^{1, *}$, J. Lavaud ${ }^{2}$, J. Serôdio ${ }^{3}$, J. L. Mouget $^{4}$, P. Cartaxana ${ }^{5}$, P. Rosa ${ }^{6}$, \\ L. Barille ${ }^{6}$, V. Brotas ${ }^{5}$, B. M. Jesus ${ }^{5,7}$ \\ ${ }^{1}$ School of Earth, Ocean and Planetary Sciences, Cardiff University, Main Building, Park Place, Cardiff CF10 3YE, UK \\ ${ }^{2}$ UMR CNRS 6250 'LIENSs', Institute for Coastal and Environmental Research (ILE), University of La Rochelle, \\ 2 rue Olympe de Gouges, 17042 La Rochelle Cedex, France \\ ${ }^{3}$ Departamento de Biologia, Universidade de Aveiro, Aveiro 3810-193, Portugal \\ ${ }^{4}$ Laboratoire de Physiologie et Biochimie Végétales, Faculté des Sciences et Techniques, Université du Maine, EA2663, \\ Av. O. Messiaen, 72085 Le Mans Cedex 9, France \\ ${ }^{5}$ Centro de Oceanografia, Faculdade de Ciências da Universidade de Lisboa, Lisboa 1749-016, Portugal \\ ${ }^{6}$ EA 2160 ‘Mer, Molécules, Santé', Faculté des Sciences et Techniques, Université de Nantes, 2 rue de la Houssinière, \\ BP 92208, 44322 Nantes cedex 3, France \\ ${ }^{7}$ Centro de Biodiversidade, Genómica Integrativa e Funcional (BioFIG), Faculdade de Ciências, Universidade de Lisboa \\ Lisboa 1749-016, Portugal
}

\begin{abstract}
Intertidal soft sediment microphytobenthic biofilms are often dominated by diatoms, which are able to regulate their photosynthesis by physiological processes (e.g. down-regulation through the xanthophyll cycle, referred to as non-photochemical quenching, NPQ) and behavioural processes (e.g. vertical cell movement in the sediment-biofilm matrix). This study investigated these 2 processes over a $6 \mathrm{~h}$ emersion period using chemical inhibitors under 2 light treatments (ambient and constant light at $300 \mu \mathrm{mol} \mathrm{m} \mathrm{m}^{-2} \mathrm{~s}^{-1}$ ). Latrunculin A (Lat A) was used to inhibit cell movement and dithiothreitol (DTT) to inhibit NPQ. HPLC analysis for chlorophyll a and spectral analysis (Normalised Difference Vegetation Index) indicated that Lat A significantly inhibited cell movement. Photosynthetic activity was measured using variable chlorophyll fluorescence and radiolabelled carbon uptake and showed that the non-migratory, Lat A-treated biofilms were severely inhibited as a result of the high accumulated light dose (significantly reduced maximum relative electron transport rate, $\mathrm{rETR}_{\max }$ and light utilisation coefficient, $\alpha$, compared to the migratory DTT and control-treated biofilms). No significant patterns were observed for ${ }^{14} \mathrm{C}$ data, although a decrease in uptake rate was observed over the measurement period. NPQ was investigated using HPLC analysis of xanthophyll pigments (diatoxanthin and the percentage de-epoxidation of diadinoxanthin), chlorophyll fluorescence (change in maximum fluorescence yield) and the 2nd order spectral derivative index (diatoxanthin index). Patterns between methods varied, but overall data indicated greater NPQ induction in the non-migratory Lat A treatment and little or no NPQ induction in the DTT and control treatments. Overall, the data resulted in 2 main conclusions: (1) the primary response to accumulated light dose was vertical movement, which when inhibited resulted in severe down-regulation/photoinhibition; (2) diatoms down-regulated their photosynthetic activity in response to accumulated light dose (e.g. over an emersion period) using a combination of vertical migration and physiological mechanisms that may contribute to diel and/or tidal patterns in productivity.
\end{abstract}

KEY WORDS: Benthic $\cdot$ Diatom · Down-regulation $\cdot$ Migration $\cdot$ Photophysiology $\cdot$ Productivity

\section{INTRODUCTION}

Microphytobenthic biofilms at the surface of intertidal estuarine sediments are highly productive (Brotas et al. 1995, MacIntyre et al. 1996, Underwood \& Krom- kamp 1999). The regulatory mechanisms controlling the magnitude and periodicity of this productivity are partly understood as involving sun angle and tidal patterns (Pinckney \& Zingmark 1991) as well as changes in light dose exposure (Kromkamp et al. 1998, Serôdio 
\& Catarino 1999, Perkins et al. 2002, Jesus et al. 2005). For the latter, it has been hypothesised (Kromkamp et al. 1998, Serôdio \& Catarino 1999, Perkins et al. 2002, Jesus et al. 2006a) that cells optimise their position within the surface layers of a sediment biofilm, utilising sediment light attenuation to provide an optimal light environment; this is the concept of microcycling. The importance of vertical movement to regulate light exposure has recently been demonstrated thoroughly using chemical inhibition of movement (Cartaxana \& Serôdio 2008, Cartaxana et al. 2008). However, this is the first study to directly compare the roles of vertical movement, a behavioural form of photosynthetic down-regulation (e.g. Perkins et al. 2002), with physiological down-regulation in the form of non-photochemical quenching (NPQ; e.g. Lavaud 2007). Effectively, diatom cells move vertically through the sediment matrix utilising extracellular polymers in response to changes in light environment: too much light, cells move downwards; not enough light, cells move upwards. This is a simplification, however, as the cumulative effect of light exposure over time modifies this response (Perkins et al. 2002, 2006, Jesus et al. 2006b). It should be emphasised as well, that this microcycling movement over short time scales is distinct from the bulk movements of cells as vertical migration (Underwood \& Kromkamp 1999; and see the review by Consalvey et al. 2004) driven by tidal and sun angle driving forces, as originally outlined by Pinckney \& Zingmark (1991).

Why do diatom cells require an optimum light environment to maximise their photosynthetic potential? It is well known that excess light can lead to photodamage by production of free radicals and superoxides, which may lead to protein breakdown in photosystem (PS)II reaction centres, e.g. the D1 dimer (Olaizola et al. 1994, Materna et al. 2009). Cells can hence prevent such damage through 2 processes, both of which effectively down-regulate photosynthetic activity. Firstly, cells can migrate downwards away from high light that could result in a photodamaging light dose. This is effectively a behavioural form of down-regulation (Kromkamp et al. 1998, Serôdio \& Catarino 1999, Perkins et al. 2001, Mouget et al. 2008). Secondly, cells can down-regulate by diverting excess light energy away from PSII reaction centres via alternative energy pathways (Ting \& Owens 1993, Lavaud et al. 2002a, Goss et al. 2006, Lavaud 2007, Serôdio et al. 2008). This physiological process of down-regulation is often referred to as NPQ as it quenches the energy using energy conversions with no photochemical output. The process utilises energisation of the thylakoid membrane by generation of a proton gradient, which induces de-epoxidation of diadinoxanthin (DD) to diatoxanthin (DT) known as the xanthophyll cycle
(Lavaud et al. 2002a, 2004, Goss et al. 2006, Lavaud 2007). DT competes for light energy with chlorophyll pigments in the light harvesting complexes, hence diverting the energy away from the pathway that would lead to generation of harmful reducing agents created by over excitation of PSII reaction centres (Ruban et al. 2004, Lavaud 2007). Diatoms are known to have a highly effective xanthophyll cycle and are able to rapidly induce NPQ in response to increasing light levels (Lavaud et al. 2004, Ruban et al. 2004, Serôdio et al. 2005, 2008, Goss et al. 2006, Lavaud 2007) even so far as to induce short-term photoacclimation through NPQ induction in the time required for $30 \mathrm{~s}$ rapid light curves, e.g. over a 4 min period (Perkins et al. 2002, 2006, Cruz \& Serodio 2008).

Diatom cells in surface biofilms can therefore respond to changing light environments, and hence accumulated historical light doses, through 2 mechanisms: vertical cell movement within the sediment matrix, or NPQ induction. These processes are now well understood, e.g. Kromkamp et al. (1998), Perkins et al. (2002), Consalvey et al. (2004), Spilmont et al. (2007) and Mouget et al. (2008) regarding lightinduced cell movement, and Lavaud (2007) and Perkins et al. (2006) regarding NPQ. However, how does the down-regulation affect net productivity and how does this vary in response to the light dose over a low tide emersion period? This study aimed to address these questions through manipulative experiments using engineered biofilms treated with chemical inhibitors, under 2 different light dose regimes. Chemical treatments comprised inhibition of cell motility using Latrunculin A (Lat A), which inhibits actin filaments involved in diatom movement without affecting photosynthetic activity (Cartaxana et al. 2008), and also the use of DL-dithiothreitol (DTT), which inhibits the deepoxidation of DD to DT, and hence inhibits NPQ induction (Lavaud et al. 2002b). These treatments were compared to controls over a $6 \mathrm{~h}$ emersion period under 2 light treatments: ambient light and a constant low light environment. Thus, the roles of cell movement and NPQ induction were compared as functions of the increasing photodose accumulated over the emersion period.

\section{MATERIALS AND METHODS}

Experimental design and sampling. Surface mud to a depth of $\sim 1 \mathrm{~cm}$ was collected on 1 July 2008 from the Alcochete mudflat, located on the eastern shore of the Tagus Estuary, Portugal ( $\left.38^{\circ} 44^{\prime} \mathrm{N}, 9^{\circ} 08^{\prime} \mathrm{W}\right)$, composed of slightly gravelly mud (Jesus et al. 2006c). All experimental measurements were carried out on the following day, 2 July 2008. The mud and surface biofilm was 
returned to the laboratory where a sub-sample was examined by light microscopy to determine the dominance of epipelic diatoms in the biofilm. The remainder of the surface mud was thoroughly mixed by hand and then evenly spread in trays to a depth of $5 \mathrm{~cm}$. A shallow layer of site water $(<2 \mathrm{~cm})$ was carefully added so as not to re-suspend the mud, and the trays were left overnight in the laboratory. The following morning, at the start of the low tide emersion predicted for the original sample site, the shallow layer of site water was removed and a spectroradiometer (see 'Spectral reflectance) was used to monitor the establishment of surface biomass in one of the sample trays. Plastic cores $(2 \times 2.5 \mathrm{~cm}$ diameter $)$ were then carefully inserted into the mud to isolate minicore sediment samples in each sediment tray for the following chemical treatments: controls (addition of filtered site water only), Lat A (dissolved in site water) to inhibit cell motility, and DTT (in site water) to inhibit conversion of DD to DT and hence inhibit NPQ. Full details of these treatments are given in the following sections. Triplicates for each chemical treatment were used to provide independent samples for the following measurements: rapid light response curves using pulseamplitude modulated (PAM)-fluorescence, spectroradiometry, sampling for pigment analysis using HPLC (minicore set 1 ) and ${ }^{14} \mathrm{C}$ radiolabelled measurement of primary productivity (minicore set 2). Hence, 6 minicores were needed for each treatment for each time sampling point ( $\mathrm{n}=3, \mathrm{~T} 1,2$ and 3 , equally spaced $2 \mathrm{~h}$ apart). Finally, the number of minicores was duplicated in a second sample tray to enable 2 light treatments to be investigated: ambient and constant light $\left(300 \mu \mathrm{mol} \mathrm{m} \mathrm{m}^{-2} \mathrm{~s}^{-1}\right)$. Note that all light levels referred to were measured with a Licor cosine corrected light meter and refer to photosynthetically active radiation, 400-700 nm. The constant light was provided by a quartz white light source (400W HPI-T Pro Philips). The experimental set up is summarised in Table 1. Ambient light (Amb) and constant low light (Con) treatments were identical other than their respective light dose exposures. Finally, all treatments were applied once the biofilm had established at the sediment surface as assessed by the stabilisation of the normalised vegetation index (NDVI) reflectance readings; hence, chemical and light treatments were applied to established surface biofilms rather than prior to upward cell migration. Measurements were taken at equal time intervals of $2 \mathrm{~h}$ at T1, T2 and T3, hence covering a $6 \mathrm{~h}$ exposure period typical for the original sample site. Experiments were carried out under ambient light on the roof of the Instituto de Oceanografia de Lisboa, Lisbon, Portugal. Engineered biofilm trays were incubated in temperature controlled water tanks to minimise potential over-heating (maximum temper-
Table 1. Experimental design overview: nesting of chemical treatments (Latrunculin A, Lat A, to inhibit cell motility; DLdithiothreitol, DTT, to inhibit non-photochemical quenching, $\mathrm{NPQ}$; and controls) within light treatment (ambient, Amb, or constant, Con) within time period (T1, 2, and 3). Measurement methods were: spectroradiometry (Spec) to measure NPQ induction and surface biomass; fluorescence to obtain rapid light curve (RLV) values; pigment analysis (Pig) for chl a, diadinoxanthin, DD and diatoxanthin, DT; labelled carbon uptake rate $\left({ }^{14} \mathrm{C}\right)$ to measure productivity. All measurements made as triplicates, i.e. 3 separate minicores (MC)

\begin{tabular}{|c|c|c|c|c|}
\hline \multirow{2}{*}{$\begin{array}{l}\text { Time } \\
\text { period }\end{array}$} & \multirow{2}{*}{$\begin{array}{c}\text { Light } \\
\text { treatment }\end{array}$} & \multirow{2}{*}{$\begin{array}{l}\text { Chemical } \\
\text { treatment }\end{array}$} & \multicolumn{2}{|c|}{ Measurement } \\
\hline & & & MC set 1 & $\mathrm{MC}$ set 2 \\
\hline \multirow[t]{6}{*}{ T1 } & \multirow[t]{3}{*}{ Amb } & Lat A & Spec, RLC, Pig & ${ }^{14} \mathrm{C}$ \\
\hline & & DTT & Spec, RLC, Pig & ${ }^{14} \mathrm{C}$ \\
\hline & & Controls & Spec, RLC, Pig & ${ }^{14} \mathrm{C}$ \\
\hline & \multirow[t]{3}{*}{ Con } & Lat A & Spec, RLC, Pig & ${ }^{14} \mathrm{C}$ \\
\hline & & DTT & Spec, RLC, Pig & ${ }^{14} \mathrm{C}$ \\
\hline & & Controls & Spec, RLC, Pig & ${ }^{14} \mathrm{C}$ \\
\hline \multirow[t]{6}{*}{$\mathrm{T} 2$} & \multirow[t]{3}{*}{$\mathrm{Amb}$} & Lat A & Spec, RLC, Pig & ${ }^{14} \mathrm{C}$ \\
\hline & & DTT & Spec, RLC, Pig & ${ }^{14} \mathrm{C}$ \\
\hline & & Controls & Spec, RLC, Pig & ${ }^{14} \mathrm{C}$ \\
\hline & \multirow[t]{3}{*}{ Con } & Lat A & Spec, RLC, Pig & ${ }^{14} \mathrm{C}$ \\
\hline & & DTT & Spec, RLC, Pig & ${ }^{14} \mathrm{C}$ \\
\hline & & Controls & Spec, RLC, Pig & ${ }^{14} \mathrm{C}$ \\
\hline \multirow[t]{6}{*}{ T3 } & \multirow[t]{3}{*}{ Amb } & Lat A & Spec, RLC, Pig & ${ }^{14} \mathrm{C}$ \\
\hline & & DTT & Spec, RLC, Pig & ${ }^{14} \mathrm{C}$ \\
\hline & & Controls & Spec, RLC, Pig & ${ }^{14} \mathrm{C}$ \\
\hline & \multirow[t]{3}{*}{ Con } & Lat A & Spec, RLC, Pig & ${ }^{14} \mathrm{C}$ \\
\hline & & DTT & Spec, RLC, Pig & ${ }^{14} \mathrm{C}$ \\
\hline & & Controls & Spec, RLC, Pig & ${ }^{14} \mathrm{C}$ \\
\hline
\end{tabular}

atures measured at the sediment surface during the experimental period were $35^{\circ} \mathrm{C}$, comparable to those measured in situ). Light dose was calculated for each time point, T1, T2, T3, by integrating the light measurements using a Licor cosine corrected light meter every 30 min over the preceding time period.

Chemical preparation and application. Controls: $400 \mu \mathrm{l}$ of filtered site water was added to all cores to mimic chemical treatments but without addition of DTT or Lat A (see below).

DTT: DTT (Sigma) was prepared as a fresh stock on the morning of the experimental period. A stock solution of $20 \mathrm{mM}$ (in ethanol) was diluted 100 times in freshly filtered site water to reach a final concentration of $200 \mu \mathrm{M}$. To each core, $400 \mu \mathrm{l}$ of this solution were added in order to cover the whole surface of the sediment. Given the dimensions of the cores, the amount of DTT added in each core was $0.17 \mu$ mol. This amount of DTT was previously determined to be sufficient to virtually fully inhibit the conversion of DD into DT in a $10 \mu \mathrm{g} \mathrm{chl} \mathrm{a} \mathrm{ml}{ }^{-1}$ suspension of Phaeodactylum tricornutum (100\% inhibition with $0.2 \mu \mathrm{mol}$ DTT) (Lavaud et al. 2002b). 
Lat A: A concentrated Lat A solution (1 mM) was prepared as a fresh stock on the morning of the experimental period by dissolving purified Lat A (Sigma-Aldrich) in dimethylsulfoxide. A solution of $12.5 \mu \mathrm{M}$ Lat A was prepared by dissolving the appropriate amount of the concentrated stock solution in filtered water collected at the sampling site. Small volumes of this solution (total of $300 \mu \mathrm{l}$ ) were applied to undisturbed sediment samples by carefully pipetting directly onto the sediment surface, until it formed a continuous thin layer that completely covered the sample. The amount of Lat A used was previously determined to be sufficient to virtually inhibit diatom migration in benthic biofilms (Cartaxana \& Serôdio 2008). The inhibitor was applied after the formation of the biofilm at the sediment surface during the period coinciding with the beginning of low tide at the sampling site.

Spectral reflectance. Spectral reflectance was measured using a USB2000 (Ocean Optics) with a VIS-NIR optical configuration controlled by a laptop using OOIBase $32^{\mathrm{TM}}$ software. The spectroradiometer sensor was positioned at a $45^{\circ}$ angle pointing at the centre of the minicore and measuring an area of $\sim 1 \mathrm{~cm}^{2}$. Reflectance spectra of the target surface were calculated by dividing the upwelling spectral radiance from the sediment surface $\left(L_{\mathrm{u}}\right)$ with the reflectance of a clean white polystyrene plate $\left(L_{\mathrm{d}}\right)$; both spectra were corrected for dark noise $\left(D_{\mathrm{n}}\right)$ (electronic signal measured at total darkness):

$$
\text { Reflectance }=\left(L_{\mathrm{u}}-D_{\mathrm{n}}\right) /\left(L_{\mathrm{d}}-D_{\mathrm{n}}\right)
$$

The polystyrene plates differed $<3 \%$ from a calibrated $99 \%$ reflectance standard plate (Spectralon) (Forster \& Jesus 2006). The NDVI was calculated as follows:

$$
\text { NDVI }=(\text { InfraRed }- \text { Red }) /(\text { InfraRed }+ \text { Red })
$$

where InfraRed is the average reflectance of the range $748-752 \mathrm{~nm}$, and Red is the average reflectance of the range $673-677 \mathrm{~nm}$.

Reflectance-derived indices are susceptible to background noise and are not sensitive enough to detect the DD to DT pigment conversion that occurs during the xanthophyll cycle. Using diatom cultures, Jesus et al. (2008) showed that the conversion of DD to DT causes a reflectance decrease at $508 \mathrm{~nm}$ that is proportional to DT content. However, this decrease was so small that only an index based on the second derivative spectrum was appropriate to detect it. Their DT index (DTI) used the second derivative peak at $508 \mathrm{~nm}$ normalized by the second derivative peak at $630 \mathrm{~nm}$ and showed very promising results in the determination of diatom DT content. Thus, DTI was used in the current study as a proxy for the DT present at the sediment surface.
The derivative spectra $(\delta)$ were calculated using a finite approximation method (Louchard et al. 2002), after smoothing the reflectance spectra with a natural cubic spline function (60 nodes). The second derivative $(\delta \delta)$ was chosen because in theory it eliminates the background effects and strongly enhances minute changes in the reflectance spectra. This would be ideal in intertidal estuarine sediments where the background signal can be strongly influenced by organic matter, sediment type and moisture. The second derivative spectra were only calculated for the ambient light treatment due to the high noise spectra generated by the lamps used in the constant light treatment.

Rapid light response curves. Rapid light response curves were obtained using a Walz Water-PAM fluorimeter and following the methodology of Perkins et al. (2006) except that $20 \mathrm{~s}$ light step increments were used rather than $30 \mathrm{~s}$, due to time constraints. Settings on the Water-PAM were as follows: saturating pulse at setting $10\left(\sim 8600 \mu \mathrm{mol} \mathrm{m} \mathrm{m}^{-2} \mathrm{~s}^{-1}\right.$ photosynthetically active radiation, PAR) for $600 \mathrm{~ms}$ duration; light curve settings of $20 \mathrm{~s}$ light step duration covering 0-1035 $\mu \mathrm{mol} \mathrm{m} \mathrm{m}^{-2} \mathrm{~s}^{-1}$ PAR (previously determined as adequate to produce fully saturated light curves for biofilms from this site); due to time restrictions during the experimental period, increasing light level steps using the Water-PAM programming were used rather than preferred decreasing light steps using Win Control (Perkins et al. 2006). Light curve measurements were taken in a random order between chemical treatments; however, at each time point, Amb measurements were made prior to Con measurements. Once spectral reflectance and fluorescence measurements had been made, the same minicores were destructively sampled for pigment analysis (see next section) with care to ensure that the area sampled was not that exposed to the light dose applied by the rapid light curve.

Analysis of rapid light curves also followed that described by Perkins et al. (2006) with curve fitting following the iterative solution of Eilers \& Peeters (1988) to determine coefficients $a, b$ and $c$. Following this, light curve parameters of relative maximum electron transport rate $\left(\mathrm{rETR}_{\max }\right)$, coefficient of light use efficiency $(\alpha)$ and light saturation coefficient $\left(E_{\mathrm{k}}\right)$ were calculated from the parameters $a, b$ and $c$ following the equations in Eilers \& Peeters (1988). The software used for curve fitting and regression analysis to determine curve parameters was Sigmaplot V11. NPQ was calculated as the change in maximum fluorescence yield: $\mathrm{NPQ}=\left(F_{\mathrm{m}}-F_{\mathrm{m}}{ }^{\prime}\right) / F_{\mathrm{m}}{ }^{\prime}$, where $F_{\mathrm{m}}$ was taken as the initial value recorded in the rapid light curve (e.g. after $30 \mathrm{~s}$ of darkness).

Pigment analysis. Approximately $50 \mathrm{mg}$ of freezedried sediment were extracted in $95 \%$ cold buffered 
methanol ( $2 \%$ ammonium acetate) for $15 \mathrm{~min}$ at $-20^{\circ} \mathrm{C}$, in the dark. Samples were sonicated (Bransonic, model 1210) for $30 \mathrm{~s}$ at the beginning of the extraction period. Extracts were filtered (Fluoropore polytetrafluoroethylene, PTFE, filter membranes, $0.2 \mu \mathrm{m}$ pore size) and immediately injected in a Shimadzu HPLC with photodiode array and fluorescence (excitation: $430 \mathrm{~nm}$, emmision: $670 \mathrm{~nm}$ ) detectors (Cartaxana \& Brotas 2003). Chromatographic separation was carried out using a C18 column for reverse phase chromatography (Supelcosil; $25 \mathrm{~cm}$ long; $4.6 \mathrm{~mm}$ in diameter; $5 \mu \mathrm{m}$ particles) and a 35 min elution programme. The solvent gradient followed Kraay et al. (1992) with a flow rate of $0.6 \mathrm{ml} \mathrm{min} \mathrm{m}^{-1}$ and an injection volume of $100 \mu \mathrm{l}$. Pigments were identified from absorbance spectra and retention times and concentrations calculated from the signals in the photodiode array detector or fluorescence detectors. Calibration of the HPLC peaks was performed using commercial standards from SigmaAldrich and DHI (Institute for Water and Environment, Hørsholm, Denmark). Samples were analysed for the xanthophyll pigments DD (the epoxidised form) and DT (the de-epoxidised form). The state of deepoxidation (DEP in \%) was calculated as: DT/(DD + DT) $\times 100 \%$.

Radiolabelled carbon uptake. Total primary productivity (mg C [mg chl a $]^{-1} \mathrm{~h}^{-1}$ ) was measured from subsamples of ${ }^{14} \mathrm{C}$-labelled biofilm. Minicores were incubated in situ with labelled ${ }^{14} \mathrm{C}$ sodium bicarbonate. One $\mathrm{ml}(370 \mathrm{~Bq})$ of label was added to each core and allowed to diffuse in the dark for $30 \mathrm{~min}$. After dark diffusion (Smith \& Underwood 1998), a 30 min incubation was carried out in both the Amb and the Con treatments, terminated by addition of $5 \%$ gluteraldehyde. The surface $\sim 2 \mathrm{~mm}$ of each minicore was extracted and transferred to an Eppendorf. Sediment samples were later freeze-dried and had inorganic label driven off by addition of concentrated $\mathrm{HCl}$ for $24 \mathrm{~h}$. After addition of scintillant cocktail (Optiphase Safe, Fisons), carbon uptake rates were calculated from counts obtained from a Packard Tricarb460C scintillation counter (LKB) with internal quench correction. Counts were corrected for self-quenching by the sediment using radia-

Table 2. Accumulated light dose calculated from the product of light measurement and length of exposure at each sampling time (T1, 2 and 3) for the ambient and constant light treatments. Units of light dose $=$ mole of photons $\mathrm{m}^{-2}$

\begin{tabular}{|lrc|}
\hline Sampling time & Ambient & Constant \\
\hline T1 & 1.82 & 2.16 \\
T2 & 7.83 & 4.32 \\
T3 & 20.00 & 6.48 \\
\hline
\end{tabular}

tion standard curves with and without sediment addition. Self quenching reduced counts by 2 to $5 \%$.

Statistical analysis. Significant difference was determined using 2-way ANOVA with chemical treatment (Lat A, DTT or controls) nested within light treatment (Amb or Con) nested within time (T1, 2, and 3). This resulted in triplicates for each of the 3 chemical treatments nested within 2 light treatments within 3 time points. Normality and homogeneity of variance of data were tested using the Kolmogorov-Smirnov test followed by Bartlett's or Levene's test (for normal or nonnormal data respectively). If data did not have equal variance, then a log transformation was applied (Zar 1999). In all cases, data were normal and non-parametric testing was not required. All tests were applied using Minitab V15 software.

\section{RESULTS}

\section{Accumulated light dose}

The light dose calculated for the Amb and Con light treatments (Table 2), showed a slightly higher accumulated dose for the Con treatment at T1, which was reversed by T2. However it was not until T3 that the difference in light dose between the 2 treatments was significantly large, with a light dose under Amb being 3.1 times that under Con.

\section{Migration}

Visual observation of the biofilms showed clear downward migration of cells over the experimental time period except for the Lat A treatment, which showed no difference in appearance (authors' pers. obs.). This was largely corroborated by the pigment data (chl a), which showed clear declines in surface biomass by time T3 (Fig. 1) for controls and DTT treatments under Con $\left(F_{2,26}=25.90, \mathrm{p}<0.01\right)$ and under $\operatorname{Amb}\left(F_{2,26}=14.05, \mathrm{p}<0.01\right)$, but with no pattern of decline for the Lat A treatment. Migration monitored using the spectral reflectance NDVI index (Fig. 2) showed a similar result, with a decrease in surface biomass under Amb for all 3 chemical treatments $\left(F_{2,26}=\right.$ 23.4, p < 0.01) between T2 and T3, although the percentage decline for Lat A was only half that of the DTT treatment and the controls. Under Con, no data were obtained for T1, however between T2 and T3 there was a significant $\left(F_{2,17}=18.6, \mathrm{p}<0.05\right)$ decline for the controls and DTT treatment, but no decline for the Lat A treatment. Overall, the Lat A clearly inhibited cell vertical migration compared to the other 2 treatments. 


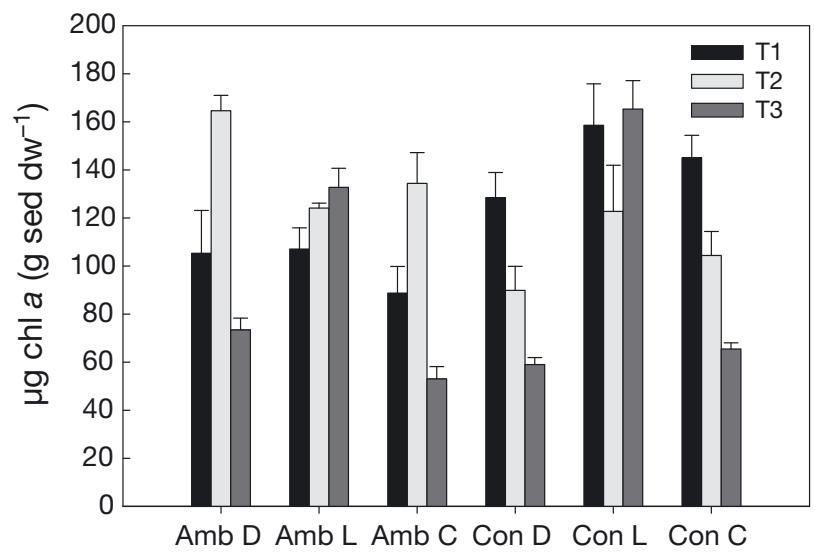

Light and chemical treatment

Fig. 1. Biomass represented as the proxy of chlorophyll a (chl a) for each chemical (D: dithiothreitol, DTT; L: Latrunculin $\mathrm{A}_{i} \mathrm{C}$ : control) and light treatment (Amb: ambient; Con: constant) over 3 time points (T1, 2 and 3). Sed dw: sediment dry weight. Values: mean $\pm \mathrm{SE}(\mathrm{n}=3)$

\section{Fluorescence data}

There was a significant decrease $\left(F_{2,26}=8.403, \mathrm{p}<\right.$ 0.01) in $\mathrm{rETR}_{\max }$ over the experimental period for all treatments, although the magnitude of the decline was lower in treatments under Con compared to those under higher ambient light (Fig. 3). There was no significant difference in $\mathrm{rETR}_{\max }$ between treatments at time T1 or T2; however, by T3, the Lat A treatment showed a significantly lower $\left(F_{2,26}=7.444, \mathrm{p}<0.05\right)$ value than controls and the DTT treatment for both light treatments. The magnitude of this difference was clearly larger under Amb compared to Con. There was

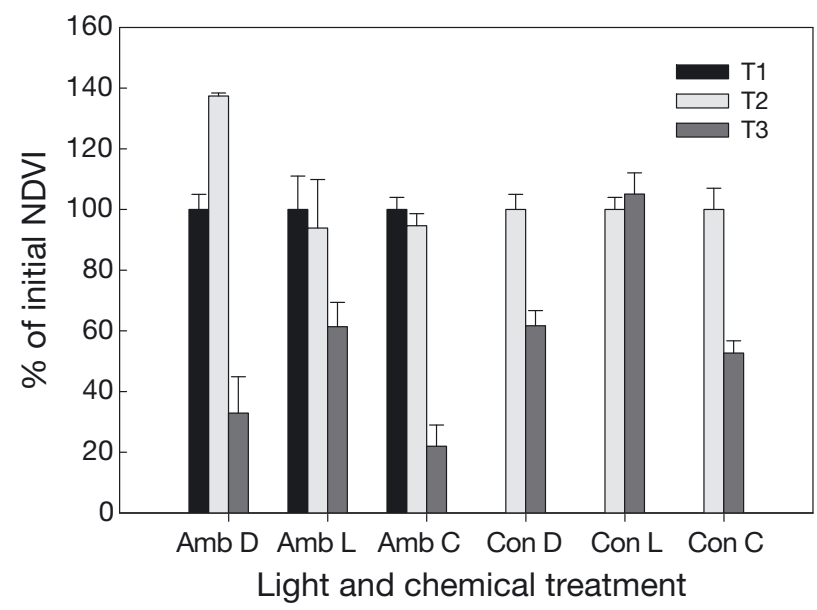

Fig. 2. Surface biomass represented as the proxy of Normalised Difference Vegetation Index (NDVI) measured using spectroradiomety. Values (mean $\pm \mathrm{SE}, \mathrm{n}=3$ ): percentage change compared to initial value at T1 for each chemical (D, $\mathrm{L}, \mathrm{C}$ ) and light treatment (Amb/Con) over 3 time points (T1, 2 and 3). See Fig. 1 for definitions

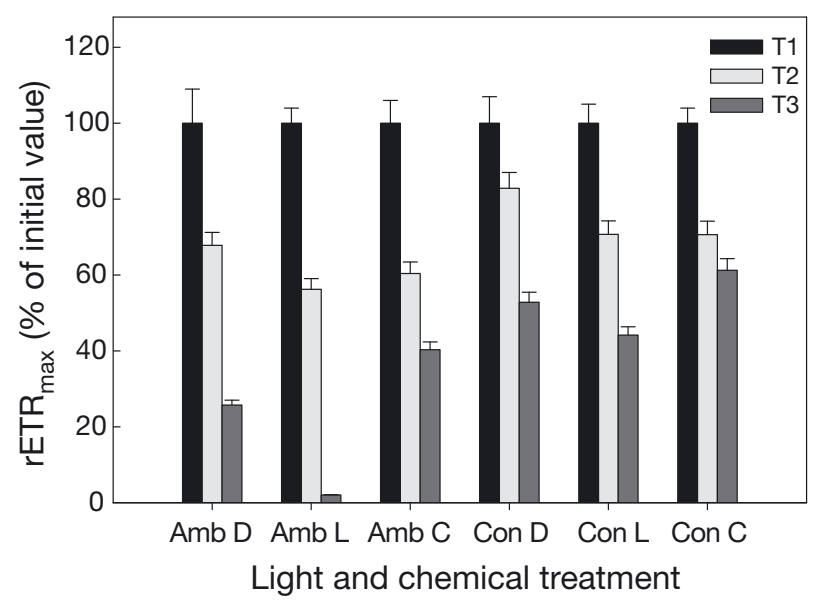

Fig. 3. Maximum relative electron transport $\left(\mathrm{rETR}_{\max }\right)$ rate as a proxy for productivity measured using variable chlorophyll fluorescence. Values (mean $\pm \mathrm{SE}, \mathrm{n}=3$ ): percentage change compared to initial value at T1 for each chemical (D, L, C) and light treatment (Amb/Con) over 3 time points (T1, 2 and 3). See Fig. 1 for definitions

no significant difference between controls and the DTT treatment under either light environment.

Under Con, $\alpha$ showed no significant pattern over time (Fig. 4), although in general, slight decreases (noticeable most for the DTT treatment) were observed. However under Amb, $\alpha$ significantly decreased $\left(F_{2,26}=6.281, \mathrm{p}<0.05\right)$ in all 3 treatments, with the decrease for the Lat A treatment being significantly greater $\left(F_{2,26}=6.810, \mathrm{p}<0.05\right)$ than either controls or DTT treatments. The value for the Lat A treatment at T3 was essentially zero (0.0005 rel. units compared to an initial value of 0.25 rel. units). The light

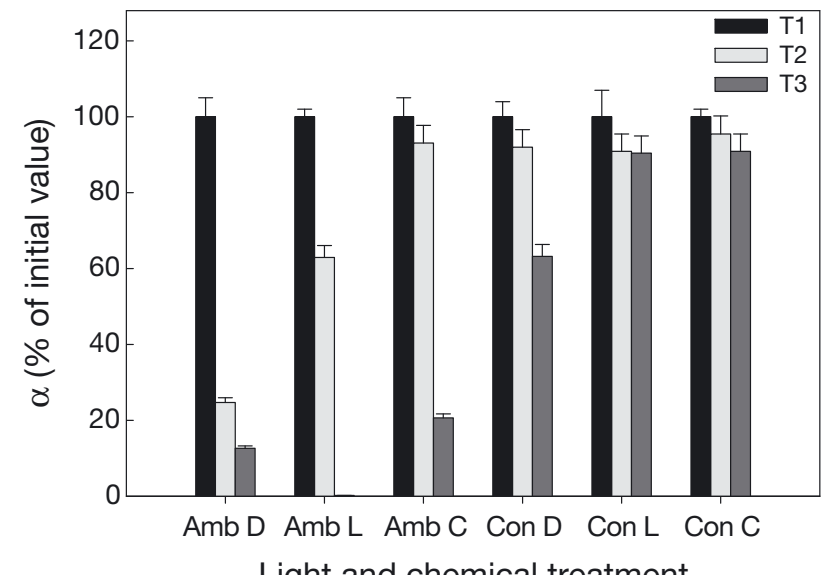

Light and chemical treatment

Fig. 4. Light utilisation coefficient $(\alpha)$ measured using variable chlorophyll fluorescence. Values (mean $\pm \mathrm{SE}, \mathrm{n}=3$ ): percentage change compared to initial value at T1 for each chemical (D, L, C) and light treatment (Amb/Con) over 3 time points (T1, 2 and 3). See Fig. 1 for definitions 


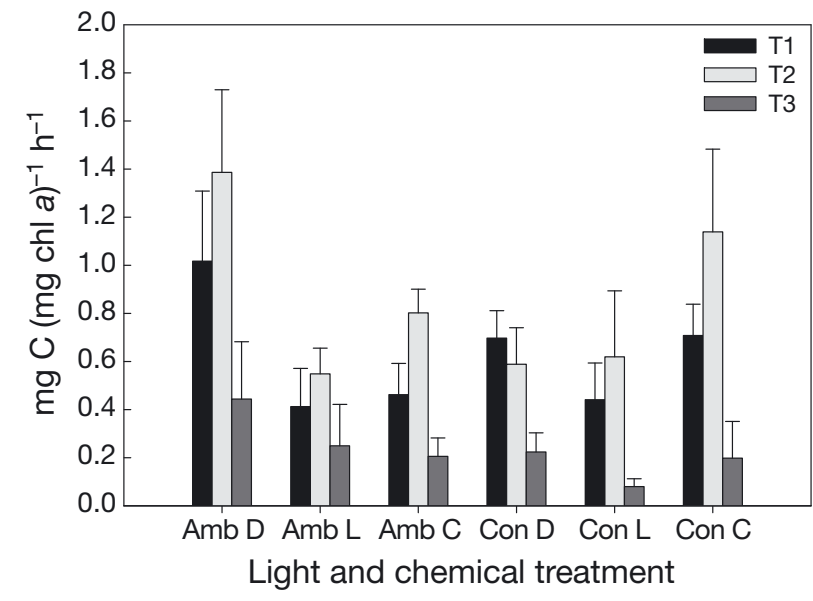

Fig. 5. Productivity measured as the uptake rate of labelled carbon $\left({ }^{14} \mathrm{C}-\mathrm{NaHCO}_{3}\right)$ for each chemical (D, L, C) and light treatment (Amb/Con) over 3 time points (T1, 2 and 3). See Fig. 1 for definitions. Values: mean $\pm \operatorname{SE}(n=3)$

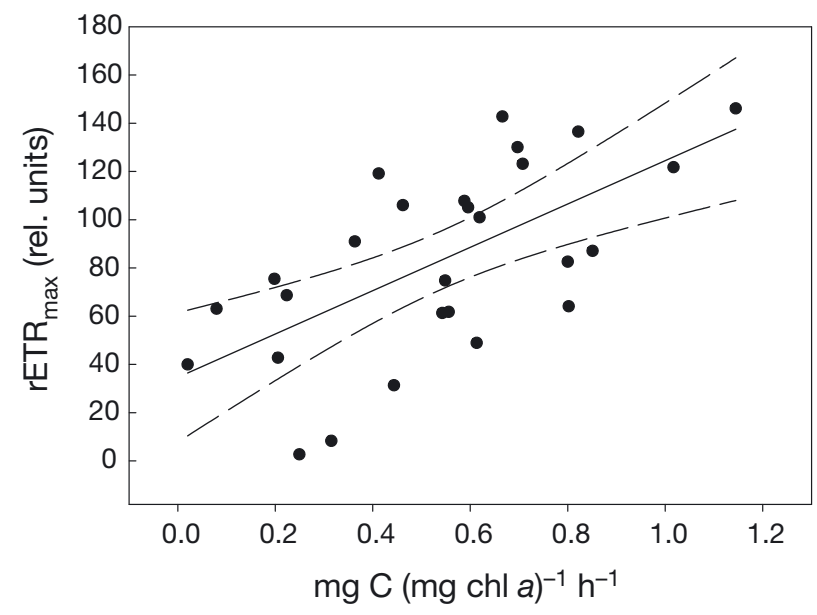

Fig. 6. Maximum relative electron transport rate $\left(\mathrm{rETR}_{\max }\right)$ presented as a function of productivity $\left({ }^{14} \mathrm{C}\right.$ uptake rate) for entire data set

saturation coefficient $\left(E_{\mathrm{k}}\right)$ followed exactly the same patterns as described above for rETR $_{\max }$ due to the magnitude of change in $\mathrm{rETR}_{\max }$ dominating the shape of the light response curves, rather than that of $\alpha$ (note $\left.E_{\mathrm{k}}=\mathrm{rETR}_{\max } / \alpha\right)$.

\section{Productivity $\left({ }^{14} \mathrm{C}\right.$ uptake rate)}

Due to a high level of variation in values between replicates of the same treatment, no significant differences were observed between chemical treatments in either Amb or Con (Fig. 5). There was also no significant difference between light treatments; however, over time, all data showed a significant decrease

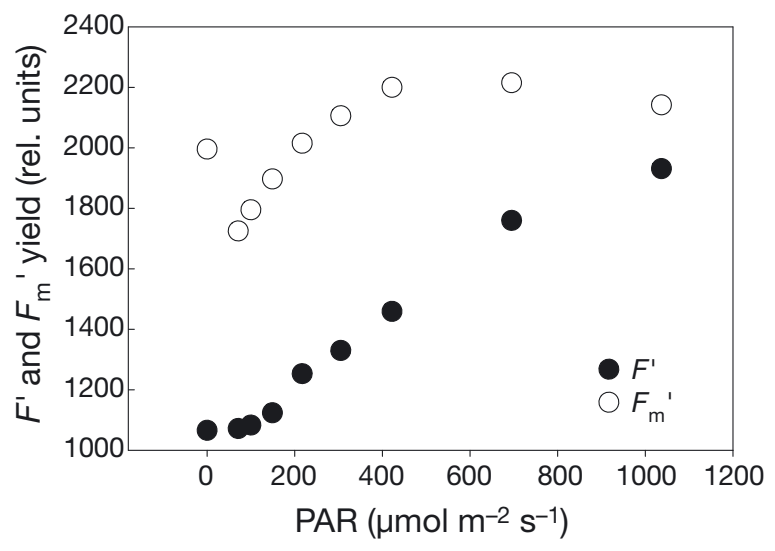

Fig. 7. Operational fluorescence yield $(F)$ and maximum fluorescence yield $\left(F_{\mathrm{m}}{ }^{\prime}\right)$ during a $20 \mathrm{~s}$ rapid light response curve. Data shown are for a control sample; however, the pattern was identical (increase in $F$ and slight decline in $F_{\mathrm{m}}{ }^{\prime}$ followed by a curvilinear increase) for all light curves measured (all 3 light treatments and at all 3 time points)

$\left(F_{2,26}=15.08, \mathrm{p}<0.01\right)$. Productivity did not correlate with $\mathrm{rETR}_{\max }$ uptake within chemical treatments, although the temporal decline for all data showed a significant correlation $(r=0.63, n=27, p<0.05)$ with $\mathrm{rETR}_{\max }$ (Fig. 6). It should be noted that the ${ }^{14} \mathrm{C}$ has a lower resolution than the fluorescence methodology, with measurements effectively integrated over the surface $5 \mathrm{~mm}$ of the sediment rather than restricted to surface and near surface analysis for the latter method.

\section{Non-photochemical quenching (NPQ)}

NPQ calculated from the change in maximum fluorescence yield: $\left(F_{\mathrm{m}}-F_{\mathrm{m}}{ }^{\prime}\right) / F_{\mathrm{m}}{ }^{\prime}$, surprisingly showed negligible induction. In all cases, the decline in quantum efficiency $\left(\Delta F / F_{\mathrm{m}}{ }^{\prime}\right)$ was the result of an increase in $F^{\prime}$ relative to $F_{\mathrm{m}}{ }^{\prime}$ (Fig. 7 ); $F_{\mathrm{m}}{ }^{\prime}$ initially declined before showing an asymptotic increase. Such a pattern resulted in small values of NPQ $(<0.20)$ at low light, followed by a decrease to near zero, or often $<0$, at light levels $\geq 320 \mu \mathrm{mol} \mathrm{m} \mathrm{m}^{-2} \mathrm{~s}^{-1}$ PAR (data not shown). DT measured by spectral analysis showed little change in the 3 treatments by T1 and T2 (Fig. 8); however, by T3 the DTI values were greater for the non-migratory Lat A treatment compared to the migratory biofilms in both controls and the DTT treatments. This method is under development, but clearly shows a treatment effect for the Lat A treatment regarding NPQ induction compared to the other 2 treatments. This overall pattern was corroborated by concomitant samples analysed by pigment analysis (Fig. 9). Data for pigment analysis expressed as DD de-epoxidation (\%), DT/chl a and DT+DD/chl a are shown in comparison with cor- 


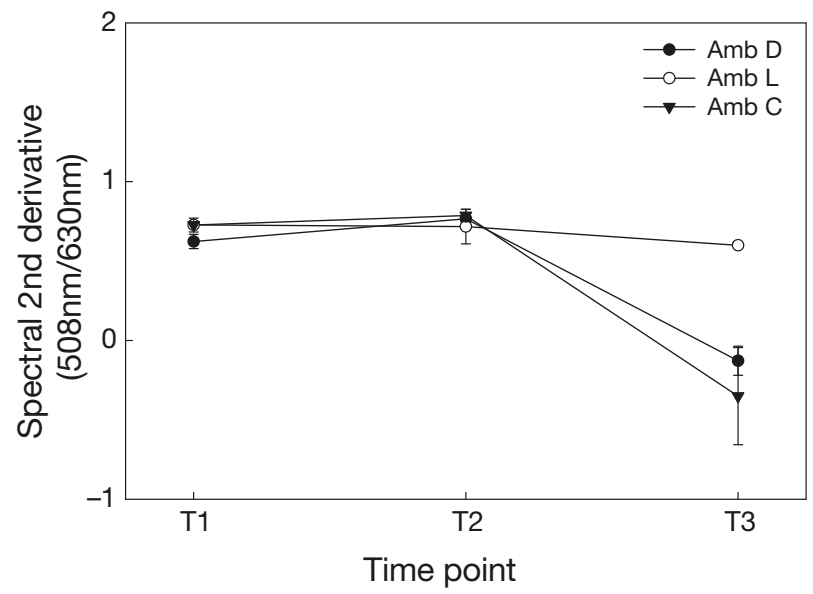

Fig. 8. Diatoxanthin index measured from the spectral 2nd derivatives $(508 / 630 \mathrm{~nm})$ for each chemical $(\mathrm{D}, \mathrm{L}, \mathrm{C})$ and light treatment (Amb/Con) over 3 time points (T1, 2 and 3).

See Fig. 1 for definitions. Values: mean \pm SE $(n=3)$

responding spectral derivative analysis. These data showed little (non-significant) change under constant low light; however, under high light, both DD de-epoxidation and DT/chl a showed significantly higher values by T3 $\left(F_{2,26}=157.67 \mathrm{p}<0.001\right)$ for the Lat A treatments compared to controls and the DTT treatment.

\section{DISCUSSION}

These data clearly indicate that, for these biofilms at least, benthic diatoms principally employ vertical migration as their first main mechanism in response to increasing light dose exposure. This is concluded from the significant photoinhibition of the Lat A treated biofilms, with probable enhanced level of physiological down-regulation through NPQ when compared to the 2 migratory treatments, DTT-treated biofilms and controls. In simple terms, cells migrated vertically in response to increasing light dose over time, but when vertical movement was inhibited by Lat A, NPQ induction increased, but not sufficiently to prevent photoinhibition. This is in agreement with the light-induced vertical movement (microcycling) proposed by Kromkamp et al. (1998), Serôdio \& Catarino (1999) and Perkins et al. (2002), and also further emphasises the role of vertical movement demonstrated in other experiments using the same chemical inhibitors (Cartaxana \& Serôdio 2008, Cartaxana et al. 2008).

Migration was significantly inhibited by the addition of Lat A (Figs. 1 \& 2), in agreement with work by Cartaxana \& Serôdio (2008) and Cartaxana et al. (2008). This was apparent through analysis of chl a pigment in the surface $2 \mathrm{~mm}$ (a comparatively low resolution method) and the surface chlorophyll proxy, NDVI.
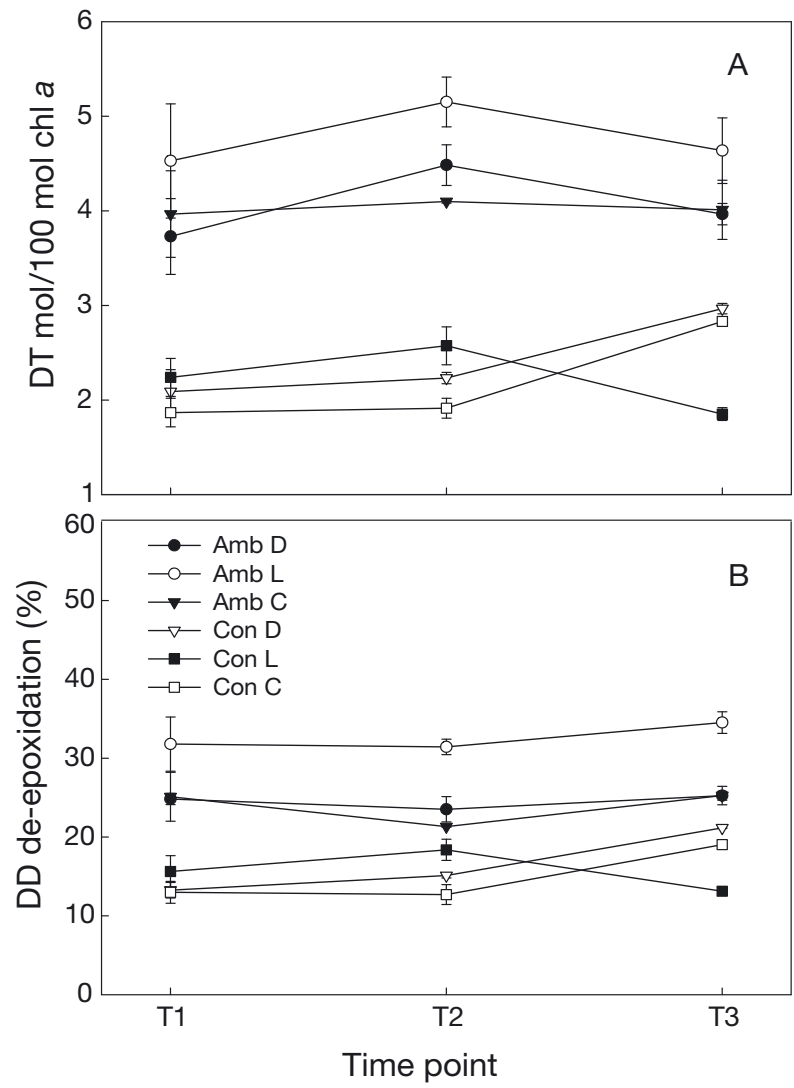

Fig. 9. Pigment data of (A) diatoxanthin (DT) and (B) percentage de-epoxidation (\%) of diadinoxanthin (DD) for each chemical ( $\mathrm{D}, \mathrm{L}, \mathrm{C})$ and light treatment (Amb/Con) over 3 time points (T1, 2 and 3). See Fig. 1 for definitions. Values: mean \pm $\mathrm{SE}(\mathrm{n}=3)$

Both methods showed no major change over the experimental period, whereas for controls and the DTTtreated biofilms, significant decreases in biomass were observed. It should be noted that there was no significant difference in biomass between DTT treatment and controls, indicating that DTT did not induce an increase or decrease in cell movement relative to controls. It should also be noted that patterns were largely the same between ambient and constant light; thus, the magnitude of the photodose did not enhance migration. There could be 2 explanations for this. Firstly, the magnitude of the vertical migration may have been predominantly determined by an endogenous tidal rhythm (e.g. Serôdio et al. 1997) rather than the light dose. Secondly, microcycling of cells (Kromkamp et al. 1998, Perkins et al. 2002) may have resulted in similar light dose exposure, irrespective of the 2 light treatments. Thus, the integrated light dose of cells cycling through the surface of the sediment was not significantly greater in the Amb treatment (this being the product of light intensity and length of exposure) compared to cells at lower light level in the 
Con treatment. It is likely that both processes played a role in the migratory pattern of the controls and DTTtreated cells; however, differentiation between these 2 driving functions was not an explicit aim of this study. It should also be noted that comparison of Amb data at T2 and Con data at T3, which related to biofilms that had been exposed to similar overall light dose, showed subtle differences in fluorescence values $\left(\mathrm{rETR}_{\max }\right.$ and $\alpha$ ), demonstrating that light dose was not the sole driving function of the differences observed. It should be noted that there was no UV light exposure under Con compared to the UV component in Amb. Mouget et al. (2008) noted that UVB exposure significantly increased photoinhibition in non-migratory (Lat A treated) biofilms, although they also stated that this was of minor importance compared to that induced by the high PAR dose experienced by the biofilms. Furthermore, NPQ induction was investigated over the $6 \mathrm{~h}$ emersion period and hence the resolution of the measurements did not analyse short term patterns in NPQ induction. It is well known that diatoms may rapidly induce NPQ in response to short-term (10s of seconds) changes in light environment (e.g. Perkins et al. 2006). The role of the comparatively long term light dose effect can be noted by the fact that it was not until T3, when the difference in light dose between the 2 treatments was greatest (Table 2), that differences between the chemical treatments were of highest magnitude.

Over the exposure period, $\mathrm{rETR}_{\max }$ decreased in all treatments (Fig. 3). This may have been the result of an endogenous diel rhythm (Underwood et al. 2005) and/or the effect of the increasing photodose. As the magnitude of the decrease was greatest under Amb, compared to the lower photodose experienced under Con, both an endogenous decrease and a photodose effect seem likely. The magnitude of this decrease in rETR $_{\max }$ was greatest for Lat A-treated biofilms, but only significantly so under Amb, indicating that the inhibition of cell vertical movement resulted in photoinhibition. This pattern was also indicated by the decline to effectively zero by $\alpha$ for the Lat A-treated biofilms under Amb (Fig. 4). Clearly, this higher photodose induced photoinhibition (possibly photodamage) when cells were unable to migrate away from the sediment surface. It should be noted that no difference was observed between the DTT-treated biofilms and the controls. Therefore it can be concluded that inhibition of NPQ (DTT treatment) had no significant impact, whereas inhibition of migration (Lat A treatment) resulted in a reduction in both $\mathrm{rETR}_{\max }$ and $\alpha$, but only when the light dose was sufficiently high compared to the Con treatment.

It is unlikely that the decrease in photosynthetic activity over the experimental period was the result of increasing environmental stress in response to experi- mental conditions. In fact, the use of the water bath may have reduced temperature stress relative to in situ temperature increases, and the biofilms showed no obvious drying out for any of the treatments. In situ warming and desiccation are likely to be equal to or greater than those experienced during this study; thus, any temporal pattern is likely to occur under in situ conditions as well. In addition, as all chemical treatments were exposed to the same stress, albeit a lower warming under constant light, experimental-induced stresses cannot explain the differences between the Lat A treatment and the controls and DTT treatment.

Productivity, when measured by ${ }^{14} \mathrm{C}$ uptake rate, showed no chemical or light treatment effects; indeed, the only significant pattern observed was an overall temporal decline over the experimental period for the whole dataset. This decline correlated with that of $\mathrm{rETR}_{\max }$ (Fig. 6) supporting the statement above that a combination of diel rhythm and light dose exposure resulted in a decrease in photosynthetic activity. The lack of any chemical treatment effect could be due to 2 reasons. Firstly, the method effectively integrates the productivity measurement over the surface $5 \mathrm{~mm}$ depth of sediment, hence resulting in a weighted average value dependent upon the biomass distribution over this depth. Secondly, the chemical treatments may not have been fully active at depth despite the pre-measurement $30 \mathrm{~min}$ incubation period, hence resulting in cell migration towards the surface of cells able to replenish the surface biofilm with photosyntheticaly active cells. The former seems more probable as an explanation, as the latter would have resulted in a surface biomass enrichment in the Lat A treatment (i.e. cells would have migrated to the surface and then been unable to migrate back down due to the chemical treatment), which was not observed.

Analysis of the data indicating induction of NPQ is not so clear cut. In all biofilms, the quenching of the photochemical efficiency $\left(\Delta F / F_{\mathrm{m}}{ }^{\prime}\right)$ was the result of an increase in $F^{\prime}$ and not a quenching of the $F_{\mathrm{m}}{ }^{\prime}$ yield. This indicates a low level or even lack of induction of NPQ as indicated by the calculated values (NPQ = $\left.\left[F_{\mathrm{m}}-F_{\mathrm{m}}{ }^{\prime}\right] / F_{\mathrm{m}}{ }^{\prime}\right)$. For the migratory biofilms, the data must be interpreted with care as downward migration between measurements of $F_{\mathrm{m}}$ and $F_{\mathrm{m}}{ }^{\prime}$ results in an increase in the calculated value of NPQ solely due to the increased distance between the cells and the fluorimeter probe (e.g. Consalvey et al. 2005, Perkins et al. 2010). However, this would have increased the magnitude in difference between the non-migratory (Lat A) and migratory (controls and DTT) treatments. In comparison, both the spectral derivative (Fig. 8) and the pigment analysis (Fig. 9) for biofilms under Amb indicated a greater level of NPQ induction in the Lat Atreated biofilms. Under Con, there was no difference 
between controls and DTT-treated biofilms and no difference between chemical treatments. Thus, a photodose effect was observed, whereby the higher ambient light photodose induced a greater level of NPQ when cell vertical movement was inhibited. DD de-epoxidation as well as the relative DT concentration (DT/chl a) both showed the same patterns. Interestingly, there was no increase in (DD+DT) concentration, indicating no de novo synthesis but a conversion of DD to DT as the primary NPQ mechanism. This is an expected result in response to high light exposure (Lavaud et al. 2004, Schumann et al. 2007). The lack of any significant effect of DTT treatment compared to controls may imply that the DTT dose was insufficient to inhibit NPQ induction. Certainly under Amb, pigment data showed an induction of NPQ in both these treatments relative to the Con treatment. However, the spectral derivate did not show this pattern, nor did fluorescence data indicate NPQ induction for any treatment. In addition, the magnitude of NPQ induction in controls and DTT treatments was significantly less than in the Lat A treatment. Therefore the overall pattern in the combined datasets indicates that cell vertical movement was more important in optimising photosynthetic activity, rather than NPQ induction.

In conclusion, this study has 2 main findings. Firstly, optimisation of photosynthetic activity in response to an increasing exposure to light (i.e. an accumulated light dose response) is largely due to vertical cell migration. Cells position themselves in the sediment surface layer such that the attenuation of light provides an optimal light environment for their photochemistry. This is in agreement with the microcycling and lightinduced vertical migration responses reported by Kromkamp et al. (1998), Serodio \& Catarino (1999) and Perkins et al. (2002). In addition, it goes towards explaining the fact that integrated biofilm light response curves examined in the literature seem to saturate at 400 to $800 \mu \mathrm{mol} \mathrm{m} \mathrm{m}^{-2} \mathrm{~s}^{-1}$ PAR (see Perkins et al. 2002, 2006, Serôdio 2003, Consalvey et al. 2005, Jesus et al. 2005, 2006b,c and others), significantly lower than ambient light levels at the sediment surface on a sunny day. It seems logical, then, that cells would position themselves in a light environment nearer to $800 \mu \mathrm{mol} \mathrm{m}{ }^{-2} \mathrm{~s}^{-1}$ PAR or lower, rather than expose themselves to the potentially photodamaging light intensities at the sediment surface. This cell migration may well be more energetically favourable than physiological down-regulation processes such as NPQ induction. It is hypothesised from this data that NPQ is a secondary response to light dose and/or a response to more rapid changes in light environment rather than a longer term increase in light dose. Secondly, these data suggest that a probable combination of vertical migration and physiological mechanisms result in a diel and/or tidal pattern of down-regulation. Underwood et al. (2005) reported diel down-regulation at the single cell level, and other studies suggest probable tidal patterns for integrated biofilm measurements (Perkins et al. 2001, Jesus et al. 2005, 2006a). Again it is logical that after adequate light exposure for photosynthate production, cells would down-regulate their photosynthetic activity. Hence, this diel pattern may be a response to integration of the light dose over time, rather than an endogenous rhythm. This study has thus shown the importance of cell vertical movement as a driving function optimising photosynthetic activity in response to light dose for benthic biofilms dominated by diatoms.

\section{LITERATURE CITED}

Brotas V, Cabrita T, Portugal A, Serôdio J, Catarino F (1995) Spatio-temporal distribution of the microphytobenthic biomass in intertidal flats of Tagus Estuary (Portugal). Hydrobiologia 300/301:93-104

Cartaxana P, Brotas V (2003) Effects of extraction on HPLC quantification of major pigments from benthic microalgae. Arch Hydrobiol 157:339-349

Cartaxana P, Serôdio J (2008) Inhibiting diatom motility: a new tool for the study of the photophysiology of intertidal microphytobenthic biofilms. Limnol Oceanogr Methods 6: 466-476

Cartaxana P, Brotas V, Serôdio J (2008) Effects of two motility inhibitors on the photosynthetic activity of the diatoms Cylindrotheca closterium and Pleurosigma angulatum. Diatom Res 23:65-74

Consalvey M, Paterson DM, Underwood GJC (2004) The ups and downs of life in a benthic biofilm: migration of benthic diatoms. Diatom Res 19:181-202

Consalvey M, Perkins RG, Underwood GJC, Paterson DM (2005) PAM fluorescence: a beginners guide for benthic diatomists. Diatom Res 20:1-22

Cruz S, Serodio J (2008) Relationship of rapid light curves of variable fluorescence to photoacclimation and non-photochemical quenching in a benthic diatom. Aquat Bot 88: 256-264

Eilers PCH, Peeters JCH (1988) A model for the relationship between light intensity and the rate of photosynthesis in phytoplankton. Ecol Model 42:199-215

Forster RM, Jesus B (2006) Field spectroscopy of estuarine intertidal habitats. Int J Remote Sens 27:3657?3669

Goss R, Ann Pinto E, Wilhelm C, Richter M (2006) The importance of a highly active and $\Delta \mathrm{pH}$-regulated diatoxanthin epoxidase for the regulation of the PS II antenna function in diadinoxanthin cycle containing algae. J Plant Physiol 163:1008-1021

Jesus B, Brotas V, Marani M, Paterson DM (2005) Spatial dynamics of microphytobenthos determined by PAM fluorescence. Estuar Coast Shelf Sci 65:30-42

Jesus B, Perkins RG, Consalvey M, Brotas V, Paterson DM (2006a) Effects of vertical migrations by benthic microalgae on fluorescence measurements of photophysiology. Mar Ecol Prog Ser 315:55-66

> Jesus B, Perkins RG, Mendes CR, Brotas V, Paterson DM (2006b) Chlorophyll fluorescence as a proxy for microphytobenthic biomass: alternatives to the current methodology. Mar Biol 150:17-28 
Jesus B, Mendes CR, Brotas V, Paterson DM (2006c) Effect of sediment type on microphytobenthos vertical distribution: modelling the productive biomass and improving ground truth measurements. J Exp Mar Biol Ecol 332:60-74

> Jesus B, Mouget JL, Perkins RG (2008) Detection of diatom xanthophyll cycle using spectral reflectance. J Phycol 44: 1349-1359

Kraay GW, Zapata M, Veldhuis M (1992) Separation of chlorophylls $C_{1}, C_{2}$, and $C_{3}$ of marine phytoplankton by reversedphase $\mathrm{C} 18$ high-performance liquid chromatography. J Phycol 28:708-712

Kromkamp J, Barranguet C, Peene J (1998) Determination of microphytobenthos PSII quantum efficiency and photosynthetic activity by means of variable chlorophyll fluorescence. Mar Ecol Prog Ser 162:45-55

Lavaud J (2007) Fast regulation of photosynthesis in diatoms: mechanisms, evolution and ecophysiology. Funct Plant Sci Biotech 1:267-287

> Lavaud J, van Gorkom H, Etienne A (2002a) Photosystem II electron transfer cycle and chlororespiration in planktonic diatoms. Photosynth Res 74:51-59

Lavaud J, Rousseau B, van Gorkom H, Etienne AL (2002b) Influence of the diadinoxanthin pool size on photoprotection in the marine planktonic diatom Phaeodactylum tricornutum. Plant Physiol 129:1398-1406

Lavaud J, Rousseau B, Etienne AL (2004) General features of photoprotection by energy dissipation in planktonic diatoms (Bacillariophyceae). J Phycol 40:130-137

Louchard EM, Reid P, Stephens CF, Davis CO, Leathers RA, Downs TV, Maffione R (2002) Derivative analysis of absorption features in hyperspectral remote sensing data of carbonate sediments. Opt Express 10:1573-1584

MacIntyre HL, Geider RJ, Miller DC (1996) Microphytobenthos: the ecological role of the 'Secret Garden' of unvegetated, shallow-water marine habitats. I. Distribution, abundance and primary production. Estuaries 19: 186-201

Materna AC, Sturm S, Kroth PG, Lavaud J (2009) First induced plastid genome mutations in an alga with secondary plastids: $p s b A$ mutations in the diatom Phaeodactylum tricornutum (Bacillariophyceae) reveal consequences on the regulation of photosynthesis. J Phycol 45:838-846

Mouget JL, Perkins RG, Consalvey M, Lefebvre S (2008) Migration or photoacclimation to prevent photoinhibition and UV-B damage in marine microphytobenthic communities. Aquat Microb Ecol 52:223-232

Olaizola M, Laroche J, Kolber Z, Falkowski PG (1994) Nonphotochemical fluorescence quenching and the diadinoxanthin cycle in a marine diatom. Photosynth Res 41: 357-370

Perkins RG, Underwood GJC, Brotas V, Snow GC, Jesus B, Ribeiro L (2001) Responses of microphytobenthos to light: primary production and carbohydrate allocation over an emersion period. Mar Ecol Prog Ser 223:101-112

> Perkins RG, Oxborough K, Hanlon ARM, Underwood GJC, Baker NR (2002) Can chlorophyll fluorescence be used to estimate the rate of photosynthetic electron transport within microphytobenthic biofilms? Mar Ecol Prog Ser 228:47-56

Perkins R, Mouget JL, Lefebvre S, Lavaud J (2006) Light response curve methodology and possible implications in

Editorial responsibility: Hans Heinrich Janssen, Oldendorf/Luhe, Germany the application of chlorophyll fluorescence to benthic diatoms. Mar Biol 149:703-712

Perkins RG, Kromkamp JC, Serôdio J, Lavaud J and others (2010) The application of variable chlorophyll fluorescence to microphytobenthic biofilms. In: Suggett D, Prasil O, Borowitzka M (eds) Chlorophyll a fluorescence in aquatic sciences: methods and applications. Dev Appl Phycol 4:237-275

Pinckney J, Zingmark RG (1991) Effects of tidal stage and sun angles on intertidal benthic microalgal productivity. Mar Ecol Prog Ser 76:81-89

Ruban A, Lavaud J, Rousseau B, Guglielmi G, Etienne A (2004) The super-excess energy dissipation in diatom algae: comparative analysis with higher plants. Photosynth Res 82: 165-175

Schumann A, Goss R, Jakob T, Wilhelm C (2007) Investigation of the quenching efficiency of diadinoxanthin in cells of Phaeodactylum tricornutum (Bacillariophyceae) with different pool sizes of xanthophyll cycle pigments. Phycologia 46:113-117

Serôdio J (2003) A chlorophyll fluorescence index to estimate short-term rates of photosynthesis by intertidal microphytobenthos. J Phycol 39:33-46

Serôdio J, Catarino F (1999) Fortnightly light and temperature variability in estuarine intertidal sediments and implications for microphytobenthos primary productivity. Aquat Ecol 33:235-241

Serôdio J, da Silva JM, Catarino F (1997) Non destructive tracing of migratory rhythms of intertidal benthic microalgae using in vivo chlorophyll a fluorescence. J Phycol 33: $542-553$

> Serôdio J, Cruz S, Vieira S, Brotas V (2005) Non-photochemical quenching of chlorophyll fluorescence and operation of the xanthophyll cycle in estuarine microphytobenthos. J Exp Mar Biol Ecol 326:157-169

> Serôdio J, Vieira S, Cruz S (2008) Photosynthetic activity, photoprotection and photoinhibition in intertidal microphytobenthos as studied in situ using variable chlorophyll fluorescence. Cont Shelf Res 28:1363-1375

Smith DJ, Underwood GJC (1998) Exopolymer production by intertidal epipelic diatoms. Limnol Oceanogr 43: $1578-1591$

Spilmont N, Migné A, Seuront L, Davoult D (2007) Short-term variability of intertidal benthic community production during emersion and the implication in annual budget calculation. Mar Ecol Prog Ser 333:95-101

Ting CS, Owens TG (1993) Photochemical and nonphotochemical fluorescence quenching processes in the diatom Pheodactylum tricornutum. Plant Physiol 101: 1323-1330

Underwood GJC, Kromkamp J (1999) Primary production by phytoplankton and microphytobenthos in estuaries. Adv Ecol Res 29:93-153

> Underwood GJC, Perkins RG, Consalvey M, Hanlon ARM, Oxborough K, Baker NR, Paterson DM (2005) Patterns in microphytobenthic primary productivity: species-specific variation in migratory rhythms and photosynthetic efficiency in mixed-species biofilms. Limnol Oceanogr 50: $755-767$

Zar JH (1999) Biostatistical analysis, 4th edn. Prentice Hall, Upper Saddle River, NJ

Submitted: April 12, 2010; Accepted: August 23, 2010 Proofs received from author(s): September 28, 2010 